Supplement of Hydrol. Earth Syst. Sci., 25, 1587-1601, 2021

https://doi.org/10.5194/hess-25-1587-2021-supplement

(C) Author(s) 2021. CC BY 4.0 License.

(c) (i)

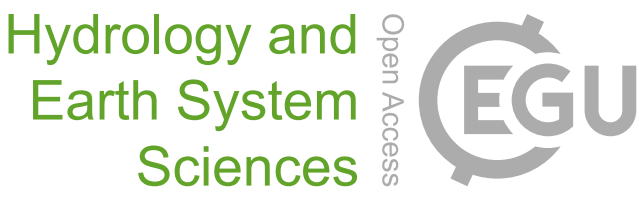

Supplement of

\title{
A standardized index for assessing sub-monthly compound dry and hot conditions with application in China
}

Jun Li et al.

Correspondence to: Xushu Wu (xshwu@ scut.edu.cn)

The copyright of individual parts of the supplement might differ from the article licence. 


\section{Supplementary content}

\section{PDSI}

The PDSI is a semi physical drought index based on the land surface water balance. The parameters of the standardized procedure of the conventional PDSI, including the climatic characteristic and duration factors, are empirically derived using the meteorological data of the central USA with its semi-arid climate. Therefore, the portability and spatial comparability of the conventional PDSI are relatively poor in other regions of the world. To develop a PDSI suited for China, the PDSI calculation procedure was revised based on long-term meteorological data of several in-situ stations distributed around China that represent the climate characteristic of mainland China. A China national standard of classification of meteorological drought with standard number of GB/T 20481-2017 provides the corrected calculation procedure of the PDSI specific for China:

$$
\begin{gathered}
Z_{\mathrm{i}}=K_{m} d_{i} \\
K_{m}=\left(\frac{16.84}{\sum_{j=1}^{12} \overline{D_{j}} K_{m}^{\prime}}\right) K_{m}^{\prime} \\
K_{m}^{\prime}=1.6 \log _{10}\left[\left(\frac{{\overline{P E_{m}}}^{\prime}+\bar{R}_{m}+\overline{R O}_{m}}{\bar{P}_{m}+\bar{L}_{m}}+2.8\right) / \bar{D}_{m}\right]+0.4 \\
\mathrm{X}_{\mathrm{i}}=0.755 X_{i-i}+Z_{i} / 1.63
\end{gathered}
$$

Where $d_{i}$ represents the moisture departure of time step $i, Z_{\mathrm{i}}$ represents the moisture anomaly index, $K_{m}$ represents the climate characteristic at month $m(m=1,2, \ldots, 12)$, 
$\overline{D_{j}}$ represents the annual mean absolute moisture departure of month $m, \bar{P}_{m}, \bar{L}_{m}, \overline{P E}_{m}$, and $\overline{R O}_{m}$ represent the annual mean precipitation, soil moisture loss, potential evapotranspiration, soil moisture recharge, and runoff of month $m$, and $X i$ represents the PDSI value of time step $i$.

\section{SPEI}

The calculation of the SPEI in this study follows the method mentioned in VicenteSerrano et al. (2010). The SPEI is based on a climatic water balance which is determined by the difference between precipitation $(P)$ and potential evapotranspiration (PET) for the month $i$ :

$$
D_{i}=P_{i}-P E T_{i}
$$

which provides a simple measure of the water surplus or deficit for the analyzed month. The PET is calculated following the FAO P-M method (Allen et al., 1998).

The calculated $D_{i}$ values are aggregated at different time scales, following the same procedure as that for the SPI. The difference $D_{i, j}^{k}$ in a given month $j$ and year $i$ depends on the chosen time scale, $k$. For example, the accumulated difference for one month in a particular year, $i$ with a 12 -month time scale is calculated according to:

$$
\begin{gathered}
X_{i, j}^{k}=\sum_{l=13-k+j}^{12} D_{i-1, l}+\sum_{l=1}^{j} D_{i, j}, \text { if } j<k \text {, and } \\
X_{i, j}^{k}=\sum_{l=j-k+1}^{j} D_{i, l}, \quad \text { if } j \geqslant k \text {, and }
\end{gathered}
$$

where $D_{i, l}$ is the P-PET difference in the $l$ th month of year $i$.

And then the log-logistic distribution is selected for standardizing the $D$ series to 
obtain the SPEI. The probability density function of log-logistic distributed variable is expressed as:

$$
f(x)=\frac{\beta}{\alpha}\left(\frac{x-\gamma}{\alpha}\right)^{\beta-1}\left[1+\left(\frac{x-\gamma}{\alpha}\right)^{\beta}\right]^{-2}
$$

Where $\alpha, \beta$, and $\gamma$ are scale, shape, and origin parameters, respectively, for $D$ values in the range $(\gamma>D<\infty)$.

Thus, the probability distribution function of the $D$ series is given by:

$$
F(x)=\left[1+\left(\frac{\alpha}{x-\gamma}\right)^{\beta}\right]^{-1}
$$

With $F(x)$ the SPEI can easily be obtained as the standardized values of $F(x)$. For example, following the classical approximation of Abramowitz and Stegun, (1965)

$$
S P E I=W-\frac{c_{0}-c_{1} W+c_{2} W^{2}}{1+d_{1} W+d_{2} W^{2}+d_{3} W^{3}}
$$

Where $W=\sqrt{-2 \operatorname{In}(p)}$ for $p \leqslant 0.05$ and $p$ is the probability of exceeding a determined $D$ value, $p=1-F(x)$. If $p>0.05, p$ is replaced by $1-p$ and the sign of the resultant SPEI is reversed. The constants are: $C_{0}=2.515517, C_{1}=0.802853, C_{2}=$ $0.010328, d_{1}=1.432788, d_{2}=0.189269$, and $d_{3}=0.001308$.

\section{A case for SAPEI calculation}

Taking the calculation of SAPEI on May 1 of each year (1961-2018) as an example, with respect to 3-month scale SAPEI, the total water surplus or deficit in three months before May 1 of each year is calculated to represent the dry and wet condition on May 1 , and thus, there are 58 values representing the dry and wet conditions on May 1 of each year from 1961 to 2018 . The water surplus or deficit was calculated through the difference between precipitation and potential evapotranspiration. For calculating a 
standardized index, a probability distribution was used to fit the daily time series (58 values), which was then transformed into a standard normal distribution (resulting in the SAPEI) using the classical approach of Barton et al. (1965).

\section{A brief introduction of copula theory}

Developed by Sklar (1959), copulas are functions that link univariate distribution functions to form multivariate distribution functions. The merit of using copulas to construct multivariate distributions is that copulas can separate the dependence effects from the marginal distribution effects. Construction of multivariate distribution is thus reduced to studying the relations among the correlated random variables if marginal distributions are given.

Considering a situation with two random variables, Sklar's Theorem states that if $F_{X, Y}(x, y)$ is a two-dimensional distribution function with marginal distributions $F_{X}(x)$ and $F_{Y}(y)$, then there exists a copula $C$ such that:

$$
F_{X, Y}(x, y)=C\left(F_{X}(x), F_{Y}(y)\right)
$$

Conversely, for any univariate distributions $F_{X}(x)$ and $F_{Y}(y)$ and any copula $C$, the function $F_{X, Y}(x, y)$ defined above is a two-dimensional distribution function with marginal distributions $F_{X}(x)$ and $F_{Y}(y)$. Furthermore, if $F_{X}(x)$ and $F_{Y}(y)$ are continuous, then $C$ is unique.

Under the assumption that the marginal distributions are continuous with probability density functions $f_{X}(x)$ and $f_{Y}(y)$, the joint probability density function then becomes

$$
f_{X, Y}(x, y)=c\left(F_{X}(x), F_{Y}(y)\right) f_{X}(x) f_{Y}(y)
$$

Where $c$ is the density function of $C$. 
Books of Nelsen (2006) introduce a copula theory in detail. 


\section{Supplementary Table}

Table S1 CMIP5 models used in this study

\begin{tabular}{|c|c|}
\hline Model name & Modeling center \\
\hline CanESM2 & Canadian Centre for Climate Modelling and Analysis, Canada \\
\hline \multirow{2}{*}{ CNRM-CM5 } & Centre National de Recherches Météorologiques/ Centre Européen de \\
\hline & Recherche et Formation Avancée en Calcul Scientifique, France \\
\hline \multirow{3}{*}{ CSIRO-Mk3.6 } & Commonwealth Scientific and Industrial \\
\hline & Research Organization/Queensland Climate Change Centre of \\
\hline & Excellence, Australia \\
\hline \multirow{2}{*}{ MIROC-ESM } & The University of Tokyo and National Institute for Environmental \\
\hline & Studies Environmental Studies \\
\hline MPI-ESM-LR & Max Planck Institute for Meteorology, Germany \\
\hline \multirow{2}{*}{ BCC-CSM1-1 } & Beijing Cliamte Center, China Meteorological \\
\hline & Administration, China \\
\hline IPSL-CM5A-LR & Institute Pierre-Simon Laplace, France \\
\hline MRI-CGCM3 & Meteorological Research Institute, Japan \\
\hline
\end{tabular}

Note: CanESM2 - Canadian Earth System Model, version 2; MPI-ESM-LR - The Max Planck Institute for Meteorology Earth System Model at Low Resolution; CNRM-CM5 - Centre National de Recherches Météorologiques Coupled Global Climate Model, version 5; CSIRO-Mk3.6 - Commonwealth Scientific and Industrial Research Organization MarkSim, version 5; MIROC-ESM - Marine-Earth Science and Technology, Earth System Model; BCC-CSM1-1 - Beijing Climate Center, China Meteorological Administration, version 1.1; IPSL-CM5A-LR - Institute Pierre Simon Laplace Model, Coupled Model, version 5, Low Resolution; MRI-CGCM3 Meteorological Research Institute, Climate General Circulation Model 3. 


\section{Supplementary Figure}
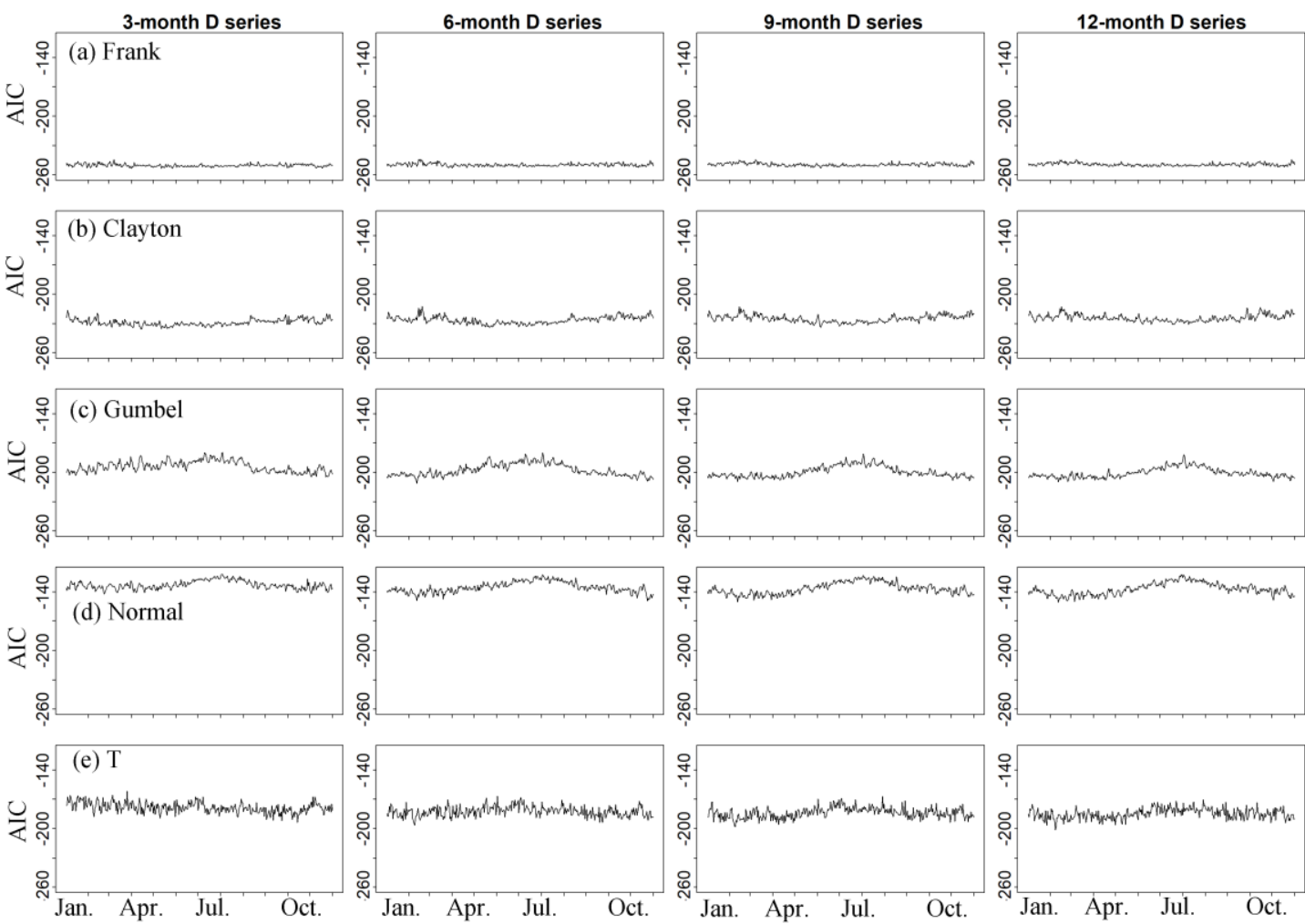

Figure S1 The AIC values for copula selection.
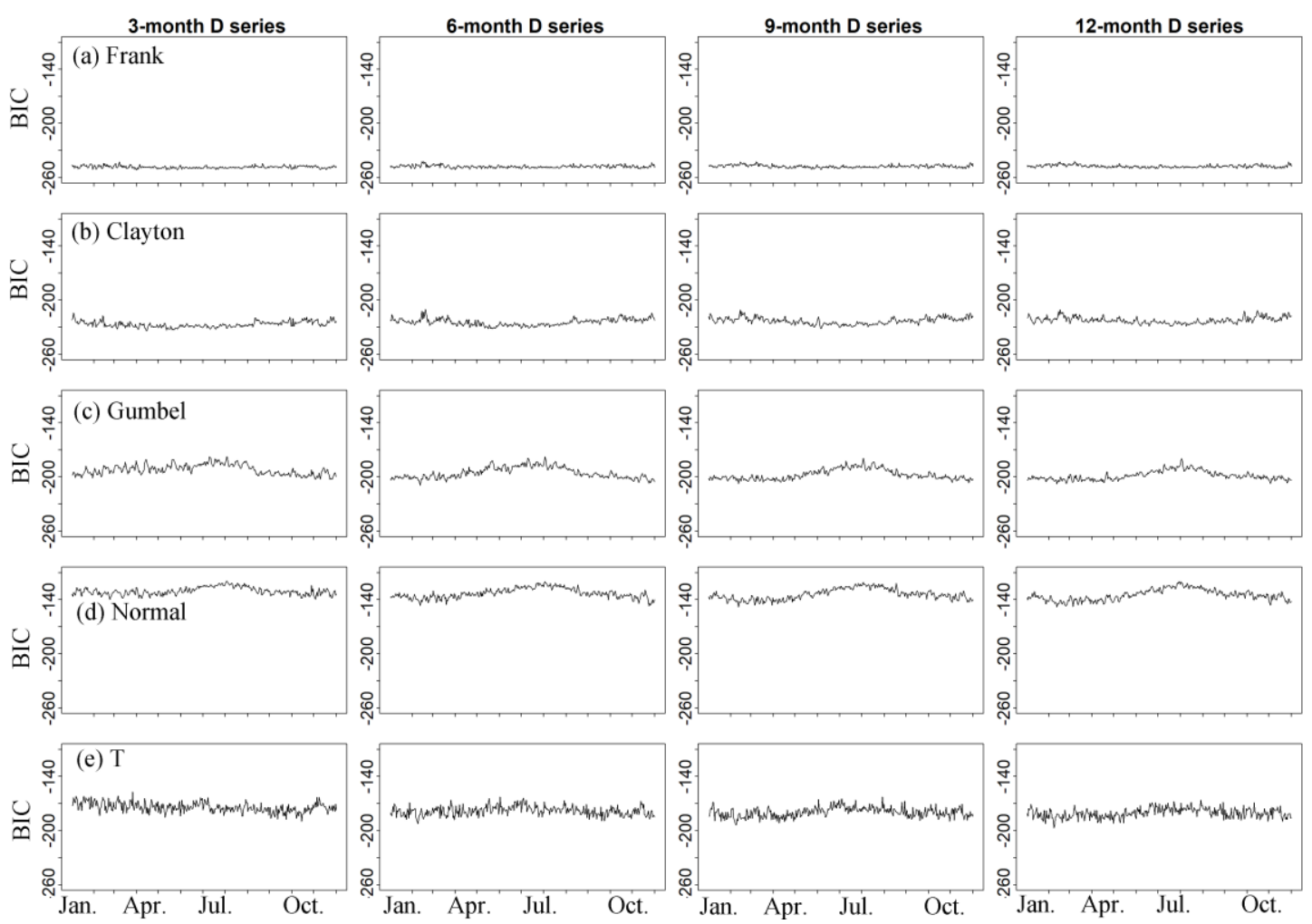

Figure S2 The BIC values for copula selection. 

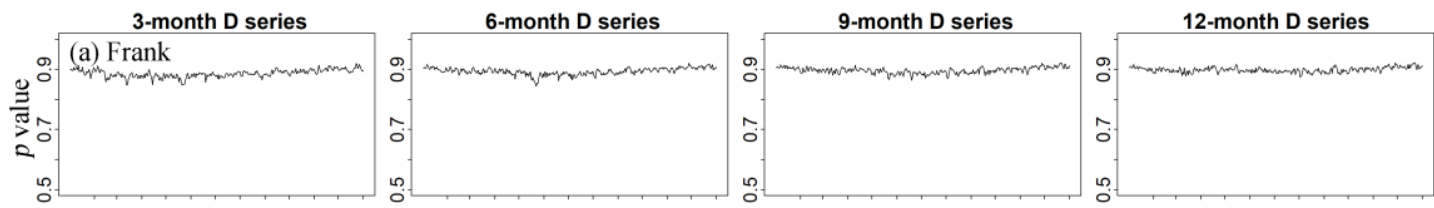

(b) Clayton
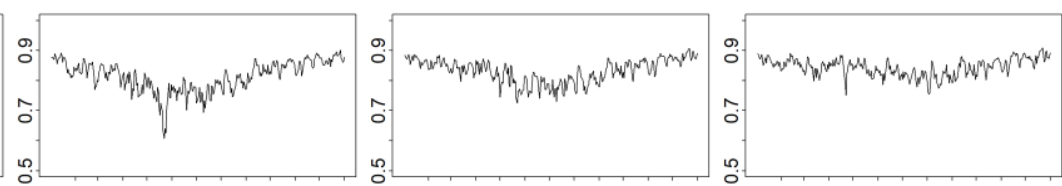

(c) Gumbel
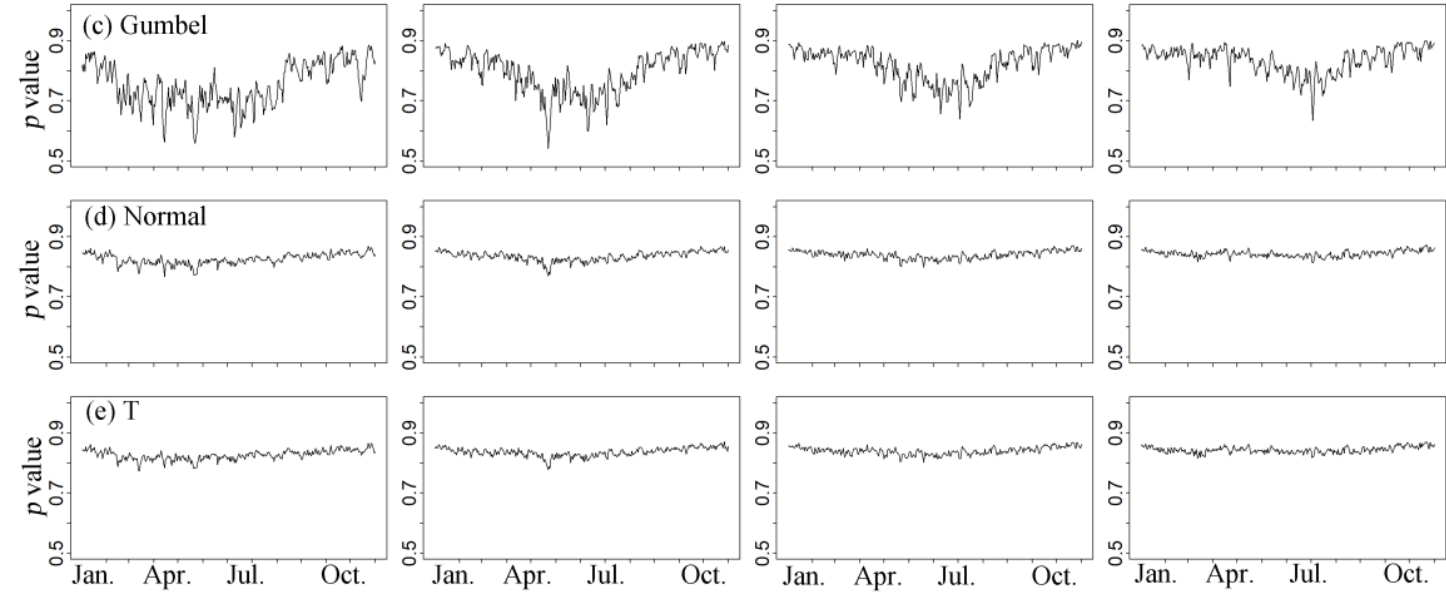

Figure S3 The $p$ value of KS test for copula selection. 


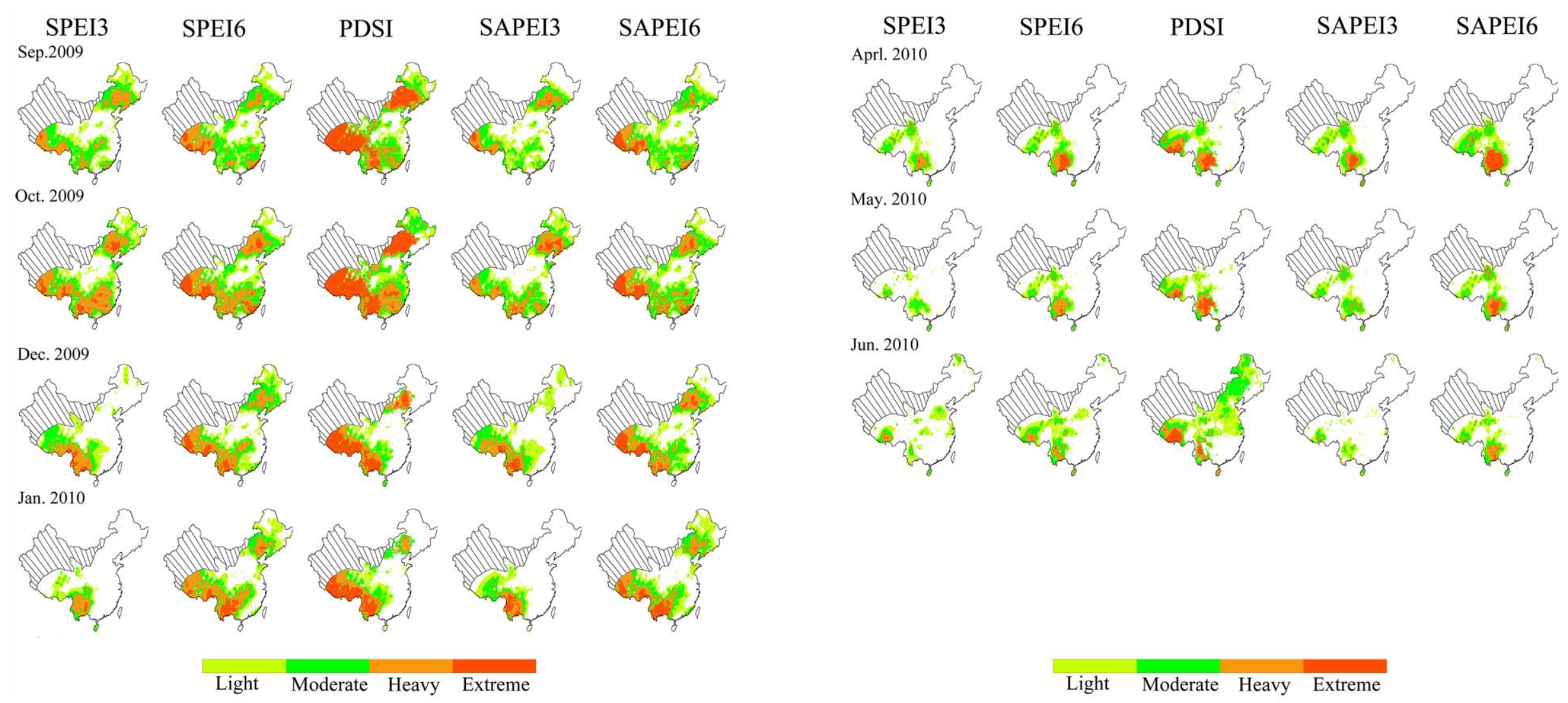

Figure S4 The monthly evolution of the 2009/10 drought in China. 


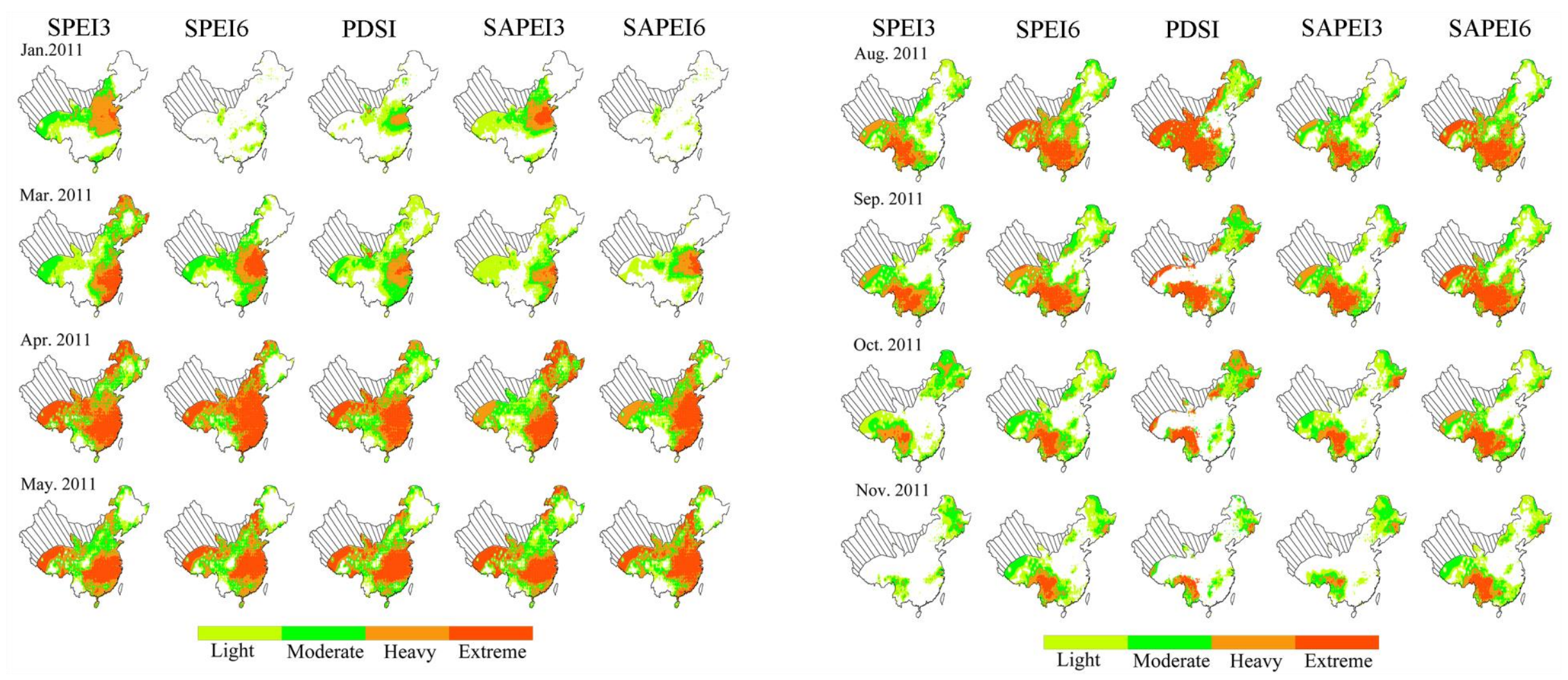

Figure S5 The monthly evolution of the 2011 drought in China. 


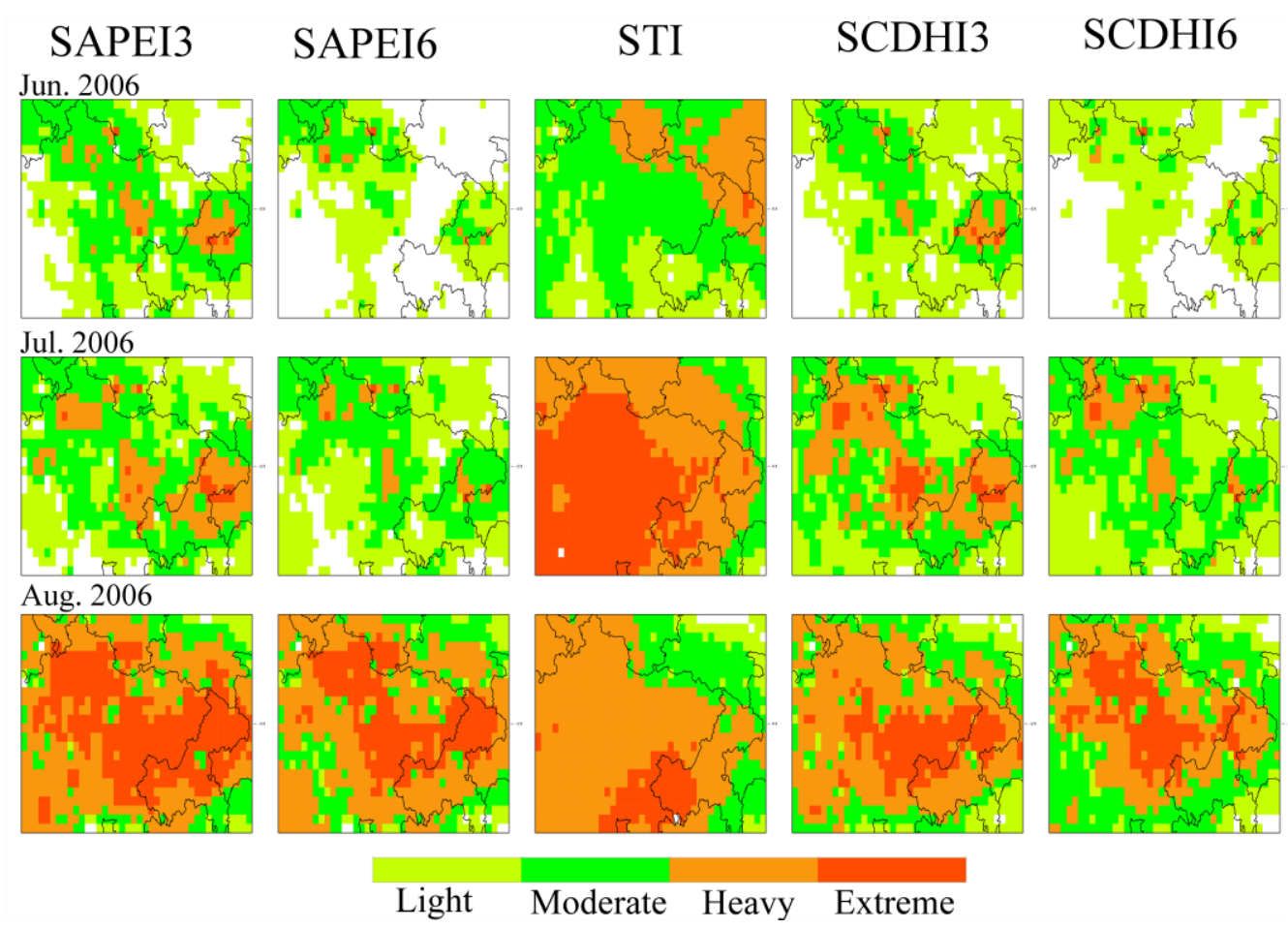

Figure S6 The monthly evolution of the compound dry and hot event in Sichuan-

Chongqing region in 2006.

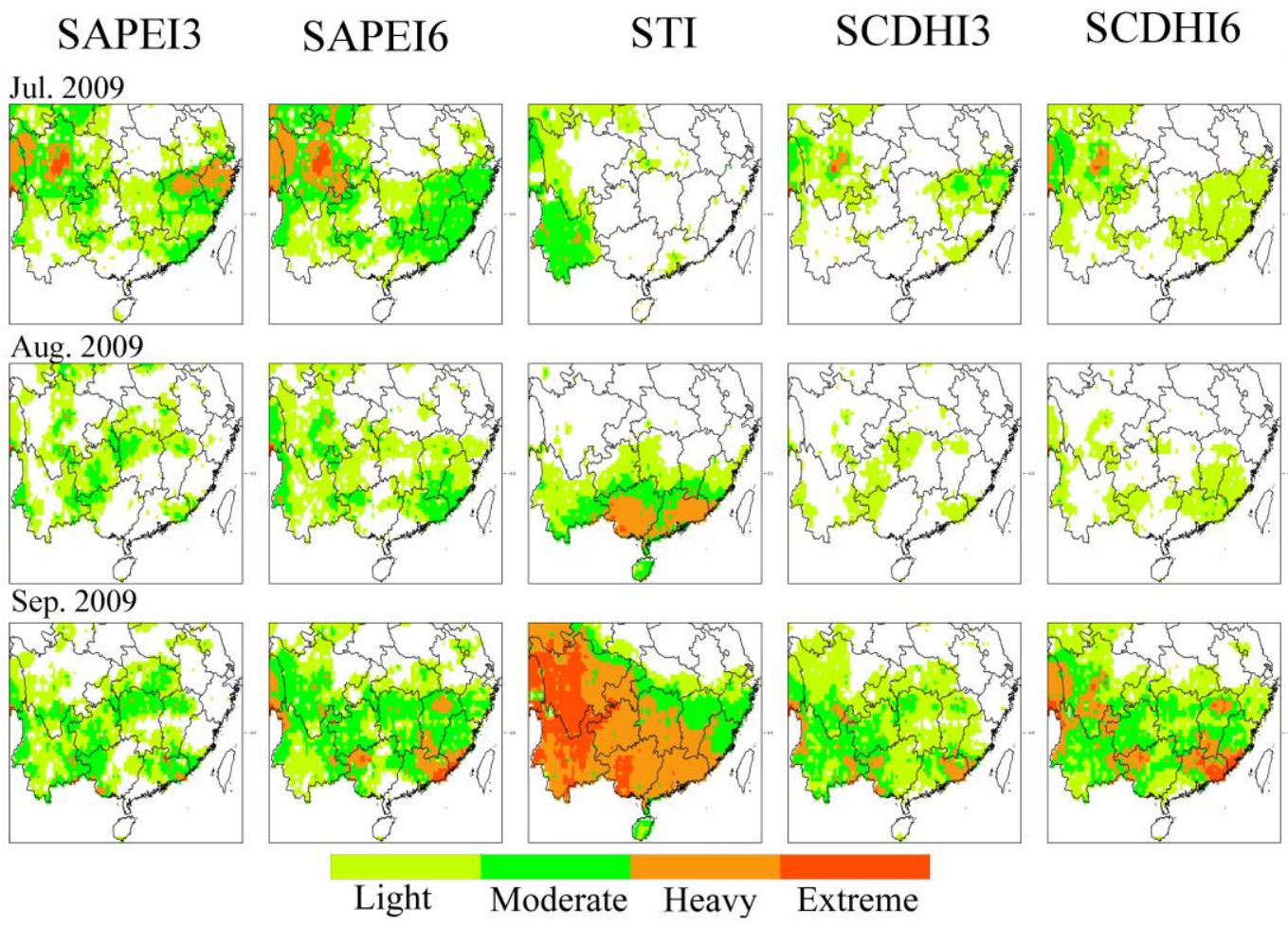

Figure S7 The monthly evolution of the compound dry and hot event in southern China in 2009. 

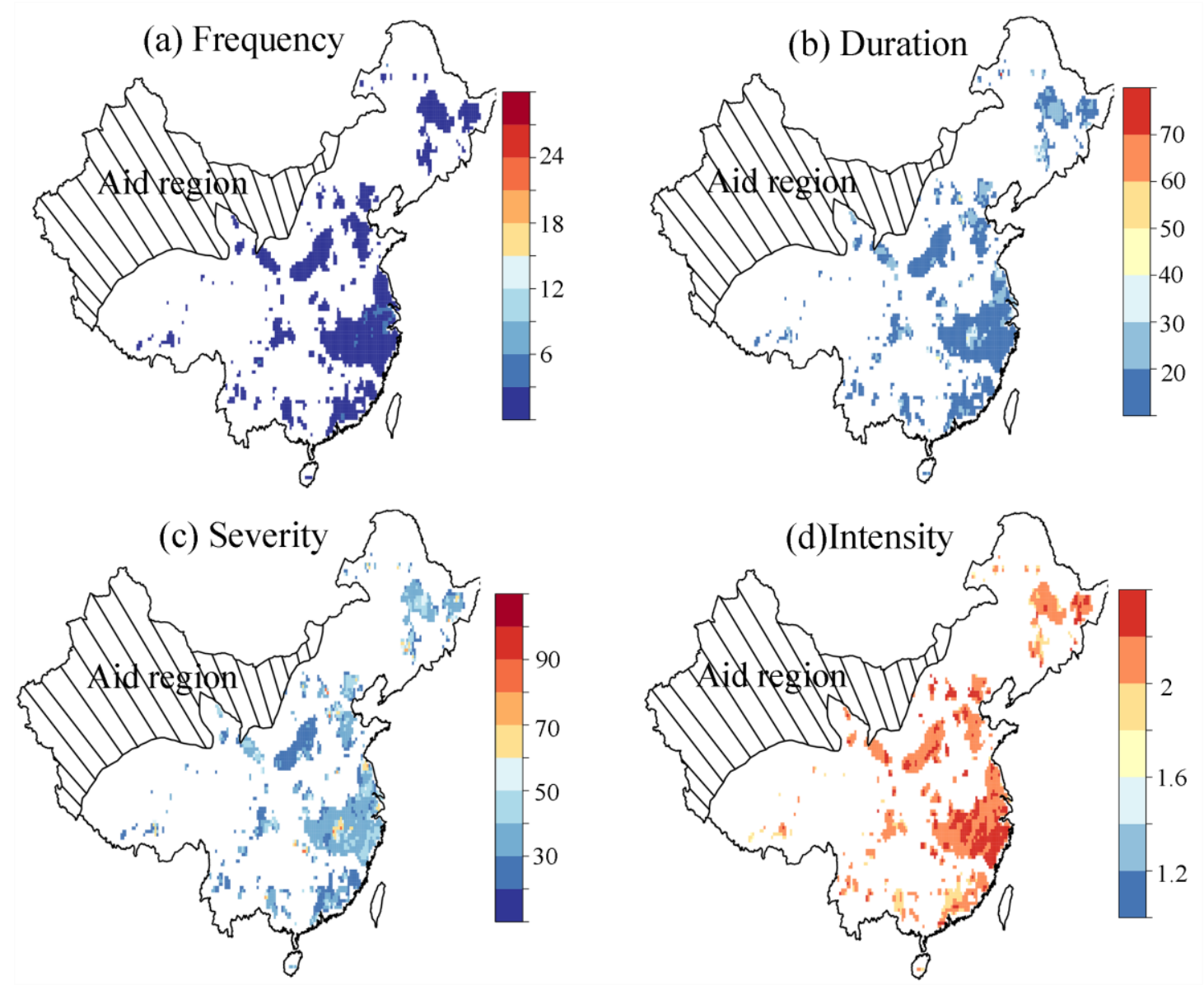

Figure S8 The spatial pattern of the characteristics of the compound dry and hot event in China from 1961 to 2018, using the threshold being -1.6 in run theory. Frequency refers to the total events during historical period; duration, severity, and intensity are the average values of all events. White color indicates there is no event. 
(a)

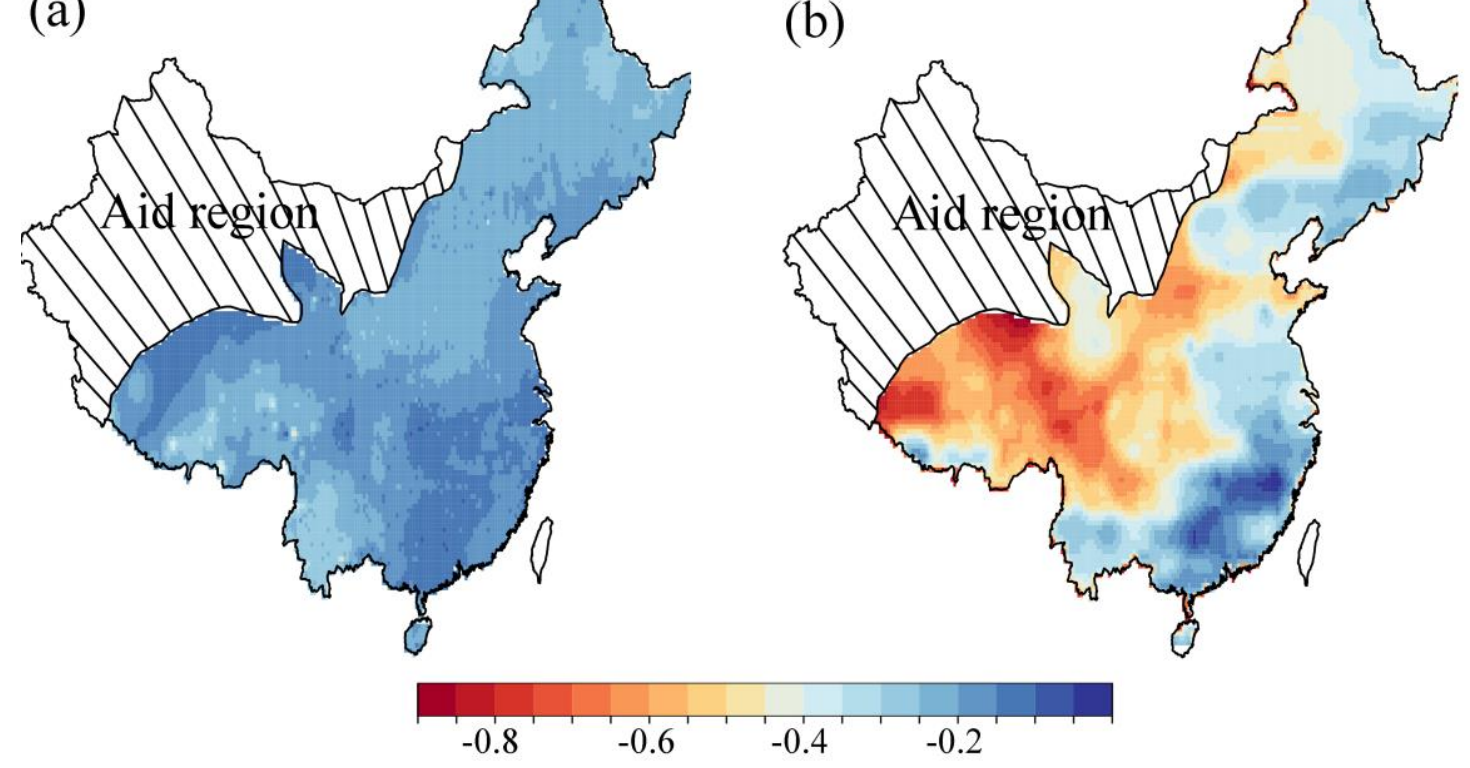

Figure S9 The correlation between SAPEI and STI. (a) the historically observational SAPEI and STI from 1961 to 2005, (b) the SAPEI and STI in CMIP5 model from 1961 to 2005 . 


\section{Reference:}

Abramowitz, M., and Stegun, I: Handbook of Mathematical Functions; Dover: NewYork, NY, USA, 1965.

Allen, R.G., Pereira, L.S., Raes, D., Smith, M.: Crop Evapotranspiration-Guideline For Computing Crop Water Requirement-FAO Irrigation and Drainage Paper No. 56. Food and Agriculture Organisation, Italy, 1998.

Barton, D. E., Abramovitz, M. and Stegun, I. A.: Handbook of Mathematical Functions with Formulas, Graphs and Mathematical Tables., J. R. Stat. Soc. Ser. A, doi:10.2307/2343473, 1965.

Nelsen, R. B.: An introduction to copulas. Springer Science \& Business Media, 2006.

Sklar, M.: Fonctions de repartition an dimensions et Leura Marges. Publ. inst. statist. univ. Paris, 8, 229-231, 1959.

Vicente-Serrano, S.M., Beguería, S., and López-Moreno, J.I.: A multiscalar drought index sensitive to global warming: the standardized precipitation evapotranspiration index. Journal of Climate 23(7), 1696-1718, 2010. 